\title{
CONTEMPORARY ART SCENARIO IN THE STATE OF ANDHRA PRADESH
}

\author{
Dr. K. Mrutyunjaya Rao \\ Sr. Assistant Professor, Department of Fine Arts, Yogi Vemana University, Kadapa, Andhra Pradesh.
}

Article DOI: https://doi.org/10.36713/epra7344

DOI No: 10.36713/epra7344

\begin{abstract}
The Art activity in the state of Andhra Pradesh was pioneered by Damerla Ramarao and Varada Venkataratnam with the help some English officers and some of their disciples. Later whole art activity is concentrated at Hyderabad till the state bifurcation in 2014. The Art education and Institutions were discussed in details. The arrival of Baroda school product has helped us to mark our self as distinct school on the cultural map of India with help of Ravinder G Reddy, V.Ramesh, T.Sudhakara Reddy, CRS Patnaik and Dr. K.Mrutyunjaya Rao. These masters has succeeded to paved a bridge between art and Contemporary art of India. Later the product of Andhra art school has spreaded all over the state and country. Two art departments emerged in the region of Rayalaseema under the lead of Dr.K. Mrutyunjaya Rao. Due to state bifurcation, the major art activity and development has gone to Telangana. The Residual Andhra Pradesh has lost so much. Many of Andhra Artists settled at other states for bread and butter. But now recovering slowly.
\end{abstract}

KEY WORDS: Damerla Rama Rao, Baroda, Contemporary, Aesthetic, Scrap Sculpture, Kadapa,

\section{INTRODUCTION}

The activities of art in Andhra Pradesh can be witnessed in the areas of Telangana and costal Andhra as united Andhra Pradesh. The development of art activity in Andhra Pradesh can be classified in two phases for the convenience of the study. The former is an initial development done in Costal Andhra and focus moved later to Hyderabad as it was made capital of the state of Andhra Pradesh. Since the last quarter of the $18^{\text {th }}$ century witnessed wonderful art activity in costal Andhra Pradesh under the Pioneership of Damerla Rama Rao. From 1940s onwards the art activity was focused at Hyderabad gradually shifted where the most of the artists migrated to for bread and butter along with their consistent efforts and experimentation in Art at Hyderabad which marked itself on the international map in respect of art activity with contribution of the telugu artists belongs to the all areas of Andhrapradesh. Soon after the independence, the art of Andhra has flourished in the hands of Laxma Gowd, P.T Reddy, PR Raju, Kapu Rajaiah, K.Seshagiri Rao, Vaikuntam Thota, DLN Reddy etc in Telangana region and G Ravinder Reddy, V. Ramesh at Andhra region in later times. 


\section{Developments in Andhra Area}

Activities of art can be viewed in Costal Andhra Pradesh since 1920s. Damerla Rama Rao (1897-1925) (fig.1) was considered as the "Father of Modern Andhra Painting". Being the product of JJ School of Art, Mumbai he has achieved an idiom that is the fusion of native Andhra themes with western forms. He was the founder of "Andhra Bharatheeya Chitrakala Parishad" an art society in 1915 and also started an Art school in 1921 in Rajahmundry by the direction of O.J Kuldre, the principal of Government Arts College, Rajahmundry 1 . O.J. Kuldre has encouraged them by introducing various idioms of their times. Varada Venkataratnam was appointed as the Principal to that art school. Under the leadership of Rama Rao, MS Prakash Rao, Varada Venkataratnam, VV Bhagiradhi (JJ School), Madeti Rajaji, Chamakur Venkata Satyanarayana, Ankala Venkata Subba Rao were

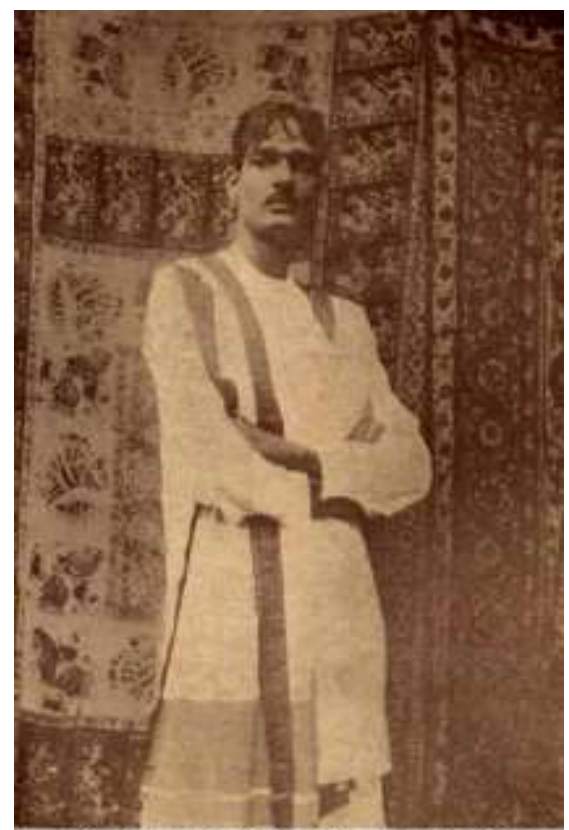

Fig.1 Late Damerla Rama Rao

excelled in combining the technique of academic naturalism and oriental wash technique of their teachers. All of their works were infused the spirit of nationalism with the impact of Bengal Revivalist art Movement. But gradually these artists were inclined to the Bombay school in term of modernity. Thus Damerla became the icon of Andhra Art. In 1925, the Bengal school sent Promod Kumar Chattergee to head the National College of Arts at Machilipatnam who was succeeded by renowned artist Adavi Bapiraju. There was an attempt nearly seven decades ago to introduce the new spirit of painting in Andhra by services of a great Bengal artist Promod Kumar Chatterjee who taught at Andhra Jateeya Kalasala at Macheleepatnam from which gave raised the number of younger artists Anand Mohan Sastry, Adavi Bapi Raju, Gurram Mallaiah, A.V. Subba Rao, V.R Chithra, and others ${ }^{2}$.

The another movement of painting was launched at Rajahmundry by Damerla Rama Rao who was taught and trained in the JJ school of Art at Mumbai. The two art movements are not rivals but experimented towards the synthesis of Art. Thus Both Chatterjee and Damerla Rama Rao have left their impressions on Andhra School of $\mathrm{Art}^{3}$. The college became the nexus for the new art movement. The art activity was gone out passively as the focus was shifted to Hyderabad. During Fifties to seventies the activity led by the Adiraju Subrahmanyam of Vijayanagaram, Rajaji, Vaddadi Papayya, CSN Patnaik student of Government College of Arts and Crafts his highly active in his medium Bronze with technically more perfect among the others.

The lyrical mysticism of art of Neo Bengal School to unimaginative realism of the Bombay School of Art. The artistic intention of both schools are different, in fact the comparision is odious; there was a much difference between them as there is difference between abstract philosophy and exact science. The contribution of Damerla Rama Rao is unforgettable on the cultural map of Andhra Pradesh who has struggled to develop a style of his own. He thought that art was dreamy, anemic and unnatural. He was too deeply immersed in the trammels of art tradition of Bombay school to break easily away from them. He

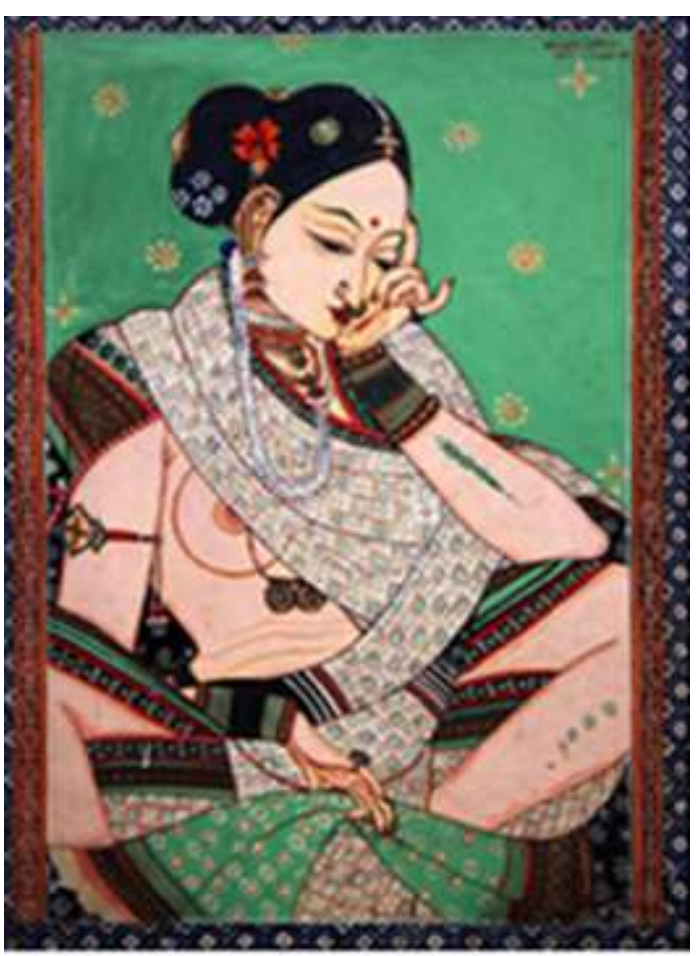

Fig.2. A Painting by A.Pydiraju sought inspiration from Greece and took much of mannerism from the works of Lord Leighton

This will reflects in his group setting of figures that closely followed by Lord Leighton. In his painting “ Ajanta Vihara" is a the Indian theme but resembles Greek settings. The pillars of Ajanta were painted in the manner of Greek as if they in height rather than shorter and bulbous. It is felt that Rama Rao is not influenced by the 
extraordinary beauties and striking poses of Ajanta women. The painting "Khatiyawar women at well " is also resembles with dress, poses are typical Indian but the composition of groups are almost like Greek art. He Has intentionally ignored the symbolism, artistic anatomy, psychological perspectives and other conventions of Indian Art. A.P. Lalit Kala Academy was established at Hyderabad in 1960 under the president ship of Nookala Narothamma Reddy and Lakshminarayana Gupta 4 as the Secretary had its own Art Gallery, where annual art exhibits were conducted known as Kala Bhavan. Late it was wound up in 80's.

The Art Scenario in Andhra Pradesh has really begun with the Department of Fine Arts at Andhra University, Visakhapatnam which was established in the year $1976^{5}$ which has played pivotal role to make so many young artists from 90s, been acknowledged as a distinguished school of art at South as well as in India. In the initial days, the department was headed by Antyakula Pydiraju, Lakshmayya Choudhary. During the Seventies sri Antyakula Pydiraju was more active and gave fresh breeze and breath to art of Andhra with his folk style (fig.2). Later decades the dimensions of the department has been completely shaped into perfect academic institution on par with other premier art institutions in India after the joining of Ravinder G Reddy, V Ramesh, T,Sudhakara Reddy, C. Ravishankar Patnaik, BM Das and Sistla Srinivas as the faculty members. In a period of a decade, their personal image in the contemporary art of India has fetched recognition and fame to department by inviting eminent artists and personalities to the department on various occasions and imbibed spirit amongst many students. Their personal and professional relations with

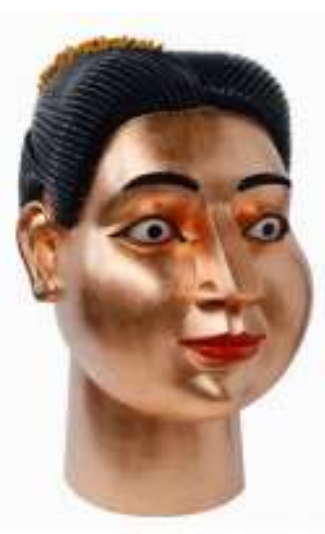

Fig.3 Ravinder G Reddy with his work

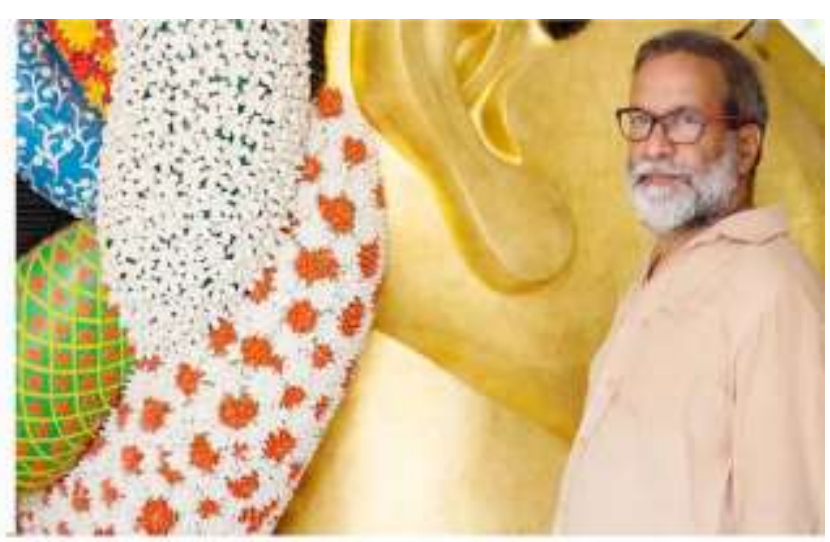
Bhupen Khakhar, Jyothi Bhatt, contemporary artists has helped to project the image of the department by inviting Bhupen Khakhar, Jan etc.
Nagji Patel, Balbir Singh Khatt, Madan Lal, K. Laxma Gowd, Rekha Rodwithya, Rm Palaniappan ena

The massive sculptures of polyester rosin and gold leaf brought fame to Ravinder Reddy at International level. In the works of Ravinder Reddy, "female form" is mostly celebrated in large size heads with wide open eyes as Hindu goddesses. Each head is embellished with rich decoration(fig.3). We easily notice that symmetry is the fundamental in his works and they unfolds society's gaze, as the way they perceive women. Prof. V.Ramesh (fig.4) is one of the most celebrated artist, Icon of Andhra whose vibes touched the off the bays and inspired many students as eminent teacher. His large canvases painted over the past decade are the subject of curiosity and debate for
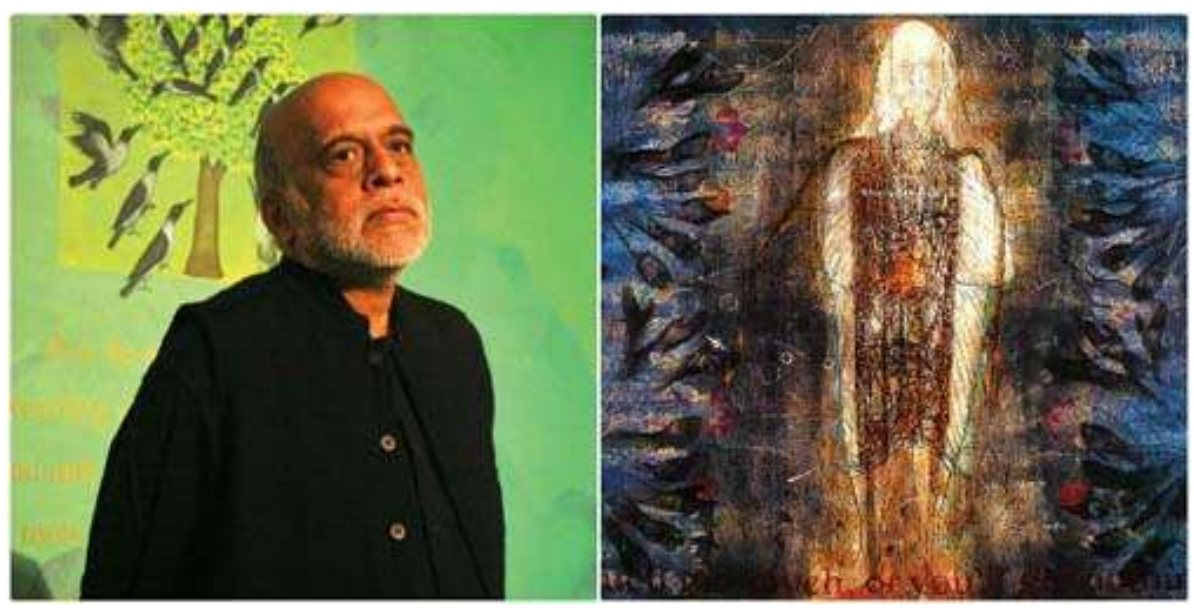
their unique concern with the idea of faith and renunciation in contemporary times. These two great personalities brought recognition to Andhra Pradesh in the field of Contemporary Art. Senior students of the department LNV Srinivas, Santhi Swaroopini, Dr.K.Mrutyunjaya Rao (fig.5), M.Venkatesam, D Simhachalam are heading the Fine Arts departments s the faculty in states of Andhra Pradesh as well as Telangana. K. Ravi contributed a lot to the art of Andhra with his numerous shows across India and abroad, now serving as teacher at 
Department of Fine Arts, Andhra University. Young Sculptor Santosh Kumar Pedagadi took up teaching as his career at School of Planning and Architecture(SPA), Vijayawada and Printmaker Kurmanadham is working in NID, Vijayawada as Assistant Professor. B. Bhaskara Rao has achieved name for is element "Tree" across the country as his signature. Sculptor S.D Hari Prasad, hailed from traditional sculptor's family from Allagadda of Kurnool ( Rayalaseema) who later turned up as National Awardee from Lalit Kala Academy. R. Giridhar Gowd, the product of the Baroda school and CAVA who lives and works in a village in Tenali. He works continuously from last two decades. Gowd's work imbibed with strong influence of Miniature and Mural paintings and preparation of the colours of his own with the inspiration of Banasthali. Vedala Ramakrishna of Vizianagaram is rendering his services as a Secretary of Lalit Kala Akademi, New Delhi. This school has acclaimed recognition for art especially in Printmaking under the supervision of T.Sudhakara Reddy who taught Printmaking, who took at most care during his teaching days at Andhra University. Young Printmakers Pratap Modi, Balaji Ponna Bandi DurgaPrasad, Subhakar, Kurmanadham, Jagadeesh Tammineni. Jagadeesh

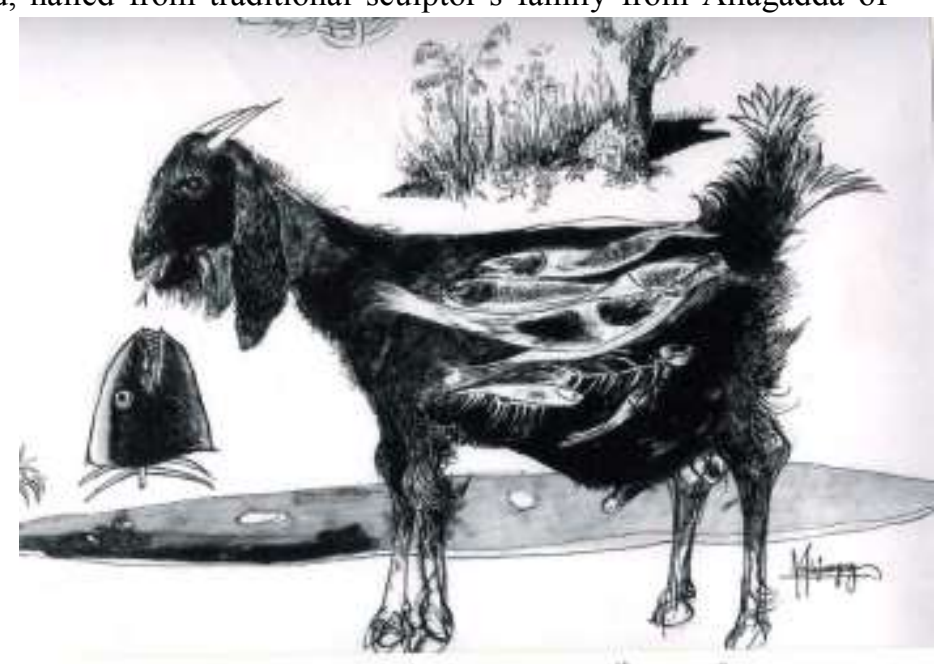

Fig.5 Drawing by K.Mrutyünjaya Rao

Tammineni is one of the most talented Printmaker, a specialist in wood cut (fig.6) and Painters K.Ravi, MTPV Prabhakar, K.Mrutyunjaya Rao, B. Bhaskar, S.Surya Rao, M. Venkatesam, Maruthi Pyla, , T.KodandaRao, T.Rajasekhar, Kanumuri Srinivas, Sculptors like Manmadha Rao, Satyanarayana, Vasupalli Appa Rao, SD.Hari

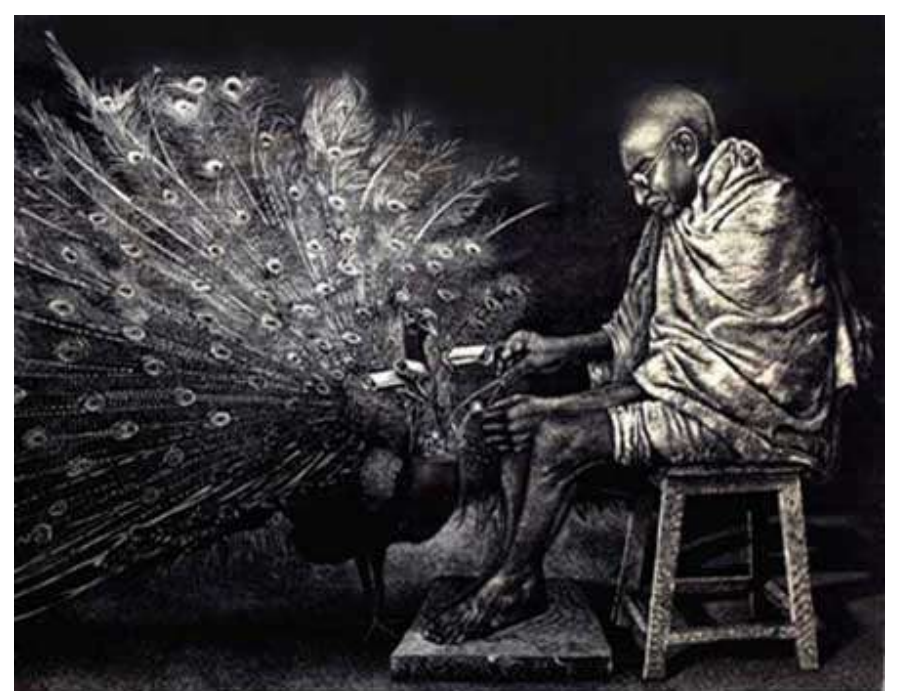

Fig.6 Wood cut by Jagadeesh Thammineni
Prasad, Kasturi Appalanaidu, Santosh Kumar Pedagadi (Fig.7), Abhishek Mandala, Syrus, Azgar Ali, Sabbavarapu Venkatesh, Sukarala Appala Raju, Srinivas Padakanadla, Ramakrishna Manyala, Ravichand, T.Govind, JSP Govind, A. Tirupati Rao, Kothuru Laxman Rao, Kodali Ravi, Srinivas Manda are very active and doing continuous work.

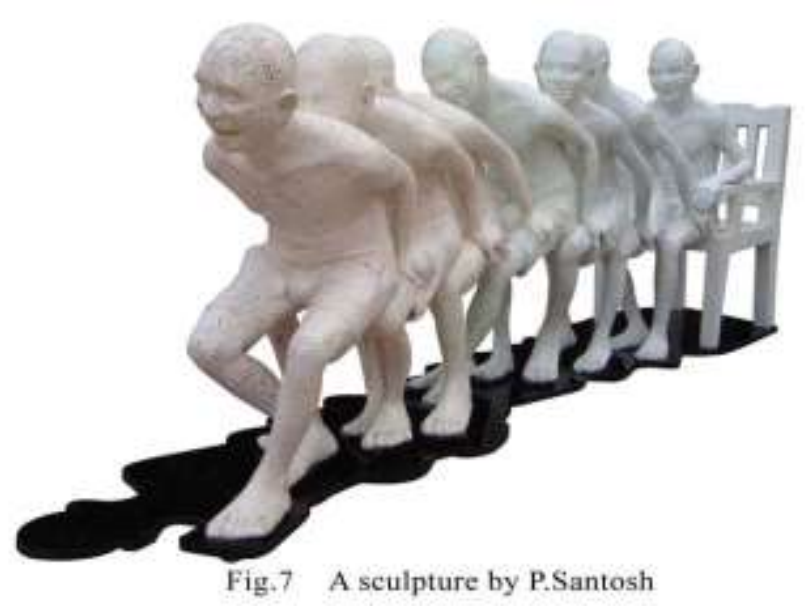


Since 2013, the passion for Automobile Scrap Sculpture is predominant in Andhra Pradesh. The above artists have participating in many Automobile Scrap Sculpture camps at places like Kurnool, Kadapa, Tirupati, Vijayawada, Visakhapatnam, Madhurai, Tanjore, Rajaasthan etc. Creative potential and meticulous work of JSP Govind in automobile scrap Sculptures brought him fame in Andhra Pradesh.There are plenty of women artists also occupied their space in the art of Andhra(fig.8). Women artists Mrs. Syeeda Ali, Shanti Swaroopini, Santi Siri, SandhyaPatnaik, Uma Vegesina, Roja Sanchana, Srilalitha Tekumalla, Divya Chinni, Sograh Khurasani, have acclaimed name through their works at International and National levels. Sograh Khurasani is a young and prominent woman artist in printmaking from Andhra Pradesh. She explores her thoughts of beauty and violence through digital print, text and videos. She composes landscapes in the form of skin, flesh, stain and scars with land, soil, valleys and mountains which are more aesthetic (fig .9). Students of this department soon raised to many heights in both Professional and Academic fronts in Andhra Pradesh and across India.

In 1992, a group of Five artists appeared on the screen of art scenario of Andhra Pradesh with common ideology on art, popularly known as "Guntur Pandavas", the term was coined by A.S Raman, the Chief editor of Illustrated weekly of India. The members included are Nagavardhan, Narasimha Rao, Vijaya Kumar, Raj Kumar and

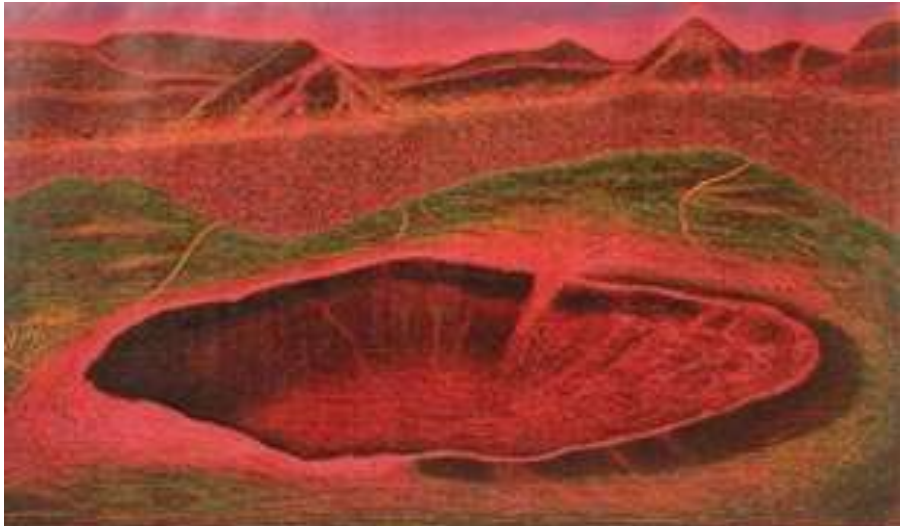

Fig.9 A Woodcut Print by Sograh Khurasani

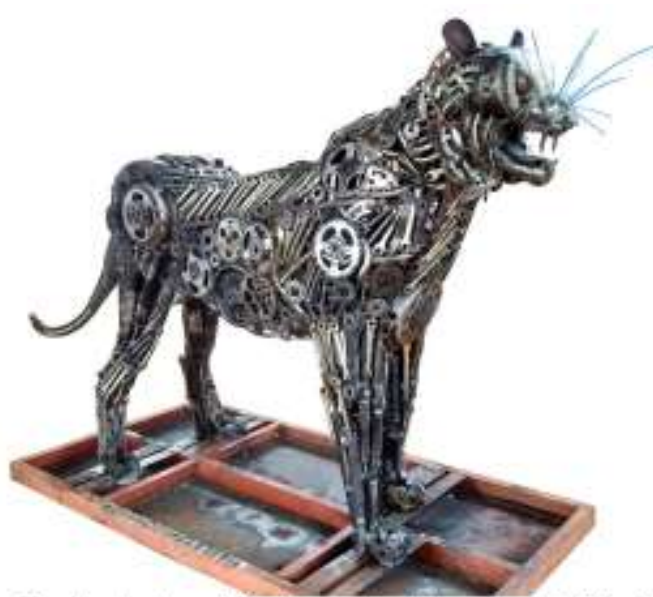

Fig.8 Automobile Scrap Sculpture by JSP Govind Osman Khan were very active at Guntur as the center for their activity of art. It was led by Vijaya Kumar and supported by Chennai based artists Rajavelu and Adimoolam. After death of Nagavardhan in 1997, having divergent opinions, in the search of livelihood, the group was dispersed, finally ended up by 20046 . Kalagramam Village was established at Visakhapatnam with hardships of Ravinder Reddy G, Botch Venkata etc as the artistic Practice center and the lead of G. Ravinder Reddy and Ravi Shankar Patnaik, V.Ramesh T. Sudhakara Reddy. Art historian Sistla Srinivas and some young people are inculcating the spirit of art History amongst the younger generations.

In 2009

another Department of Fine Arts in Yogi Vemana University, Kadapa has been established in the Rayalaseema zone which is became second art school in Andhra Pradesh. Painter, Art Writer Dr. K. Mrutyunjaya Rao as a founder faculty took lead role to establish this department. Soon, this department became famous in the state through its extensive activities in Rayalaseema as well as in

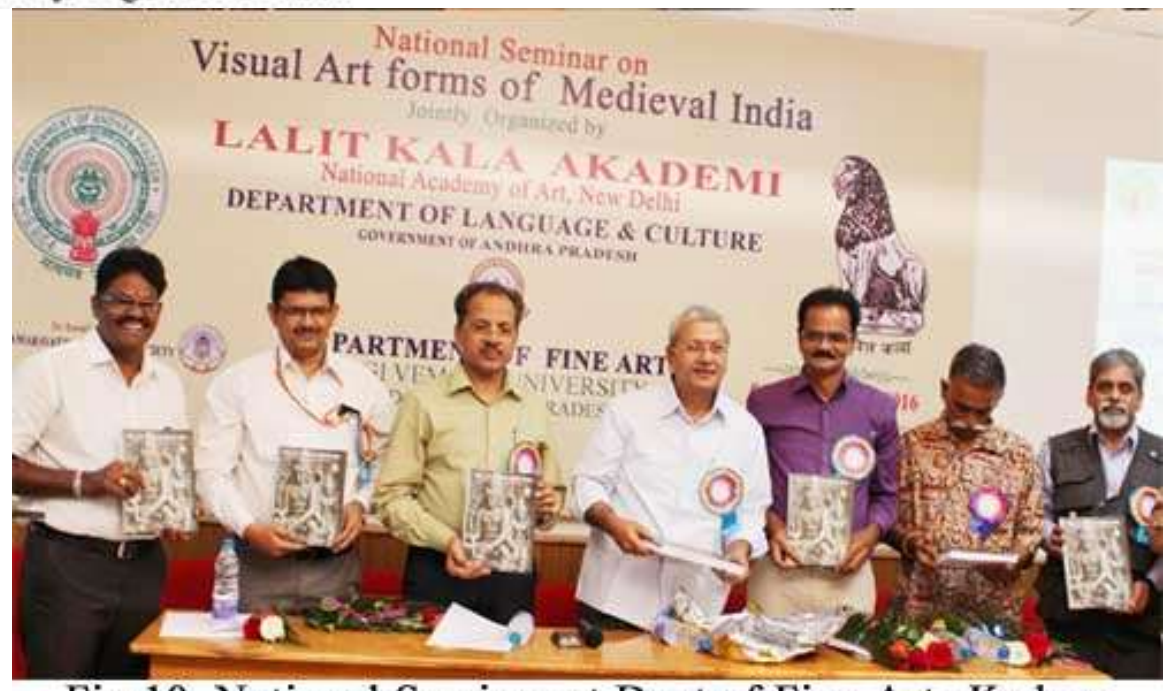

Fig.10. National Seminar at Dept of Fine Arts,Kadapa 
the state where the art has found none earlier in this region. Soon the department acclaimed fame through the teaching and its activities like National Seminar on Visual Art forms of Medieval India (fig.10) and a National Painting Camp, Artist Residency Programs sponsored by Lalit Kala Akademi, New Delhi(Fig.11). The department has conducted many activities with the help of Department of Culture and Govt of AP and Shilparamam Society.

In 2020, under the bifurcation act of 2014, Dr. YSR Architecture and Fine Arts University at Kadapa is established as a separate university, scooped out from the Jawaharlal Nehru Architecture and Fine Arts University, Hyderabad.

Dr. K.Mrutyunjaya Rao has been deputed by Govt of Andhra Pradesh to the newly established Dr. YSR Architecture and Fine Arts University at Kadapa to take part lead role in establishment under the lead of Prof. D.Vijay Kishore as its first Vice Chancellor who is known as famous Architect and Professor in Architecture from Rayalaseema. Dr. Rao took lead role and actively engaged in establishing the 6 departments such Painting, Sculpture, Animation, Applied Arts, Photography and Art History under the name of College of Art. In 2021 , the sudden demise of Prof. Ravi Shankar Patnaik, the sculptor, academician has created a vacuum in the art of Andhra Pradesh especially Fine Arts Department, Andhra University, has lost its visionary and forerunner. Now it seems the art hub of Andhrapradesh has been shifted to Kadapa. Young sculptors K. Appala Naidu, Durga Prasad, K. Sukumar Reddy and Print makers T. Jagadeesh, Barun Mandal, YB. Manohar has joined in the crew of Dr. K.Mrutyunjaya Rao. Meanwhile in the same year 2020, the another Department of Fine Arts has been started in Nagarjuna University at Guntur under the guidance Prof. V.Ramesh and Prof. CRS Patnaik. Alumni of Andhra University Srinivas Padakandla, Sekhar Babu are teaching art there.

As far as concern art galleries, The first art gallery was located at Rajahmundry named as Damerla Rama Rao Memorial Art gallery after the death of Damerla Rama Rao. By the First quarter of $20^{\text {th }}$ century Hyderabad gained popularity and achieved the status of Centre of Contemporary Art, in a course of time many private Art Galleries were established. In 1990s in Visakhapatnam several galleries named as "Abburi Kalakendram(1997)" "Threshold Art Gallery" were established, soon they disappeared in the course of time. The Threshold Gallery has now been shifted to New Delhi. The galleries in Hyderabad are blossoming along with Hyderabad. The establishment of such art galleries highly boosted the interest of art lovers and common spectators and greatly helped in the growth of contemporary art in the area of Telangana and Andhra.

In 2014, due to the division of Andhra Pradesh into two states as Andhra Pradesh and Telangana, the development done at Hyderabad as a focal point since 1940's now gone to Telangana as it was served as capital for the united Andhra Pradesh over 60 years. In result, the residual Andhra Pradesh has none in the field of art after bifurcation, not even a gallery belongs to Government. Especially space for art was little almost as it was a vacuum. Governments came after division has no time and budgetary constrains to support art and Artists. But for last five years the artists and art societies are highly alert and doing their best in promoting Art in Andhra. In the year 2015, some like minded Professional artists and academicians came together with a common ideology, sought to create a dais and then formed as group, titled as "Amaravati Visual Art Society" at Vijayawada as its center under the leadership of the artists and academicians like Dr. K.Mrutyunjaya Rao as its President, Rayana Giridhar Gowd, Teki Mrutyunjaya Rao from Guntur, Srinavas Padakandla, Santosh Pedagadi, Santosh Kumar Pedagadi who are actively working for the development of art in the state. With these latest developments, many senior artists came forward to support all the young and dynamic artists from Andhra Pradesh. But soon, due to the divergent opinions of the members, the Society is passive with little activities for past four years and disappeared on the screen of art of Andhra. Sthapathi Sivanagi Reddy is organizing many cultural activities at the Cultural Center of Vijayawada. Soon it became a prominent promoter for art and culture in Andhra Pradesh. Besides these many, organizations like Artists Association Guild, Telugu World Artists Association (TWAS) and women Art Society are actively engaged in promoting Art. The role of Kalasagar would be unforgettable for his contribution of 64.kalalu website to the art of Andhra.

Many artists like, SD Hari Prasad, Apparao Vasupalli, B.Satyanarayana, Srinivas Padakandla, Krishnamurti Panda, Prabhakar, Bhaskar Rao B, Sadhu Surya Rao T. Kodanda Rao, D. Simhachalam, Pratap Modi, Bandi Durga Prasad, Balaji Ponna, Sudhakar Tadi, Pratap Modi, Appalaraju.S, V. Prasanth, Jagadeesh Tammineni, Kurmanadham, K. Appalanaidu, Govind JSP, Durga Prasad, , G.V. Ramana Murthy, Prabhakar, Syyed, B. Bhakara Rao, M. Venkatesam, S. Surya Rao, Ravi Kiran, Imran Khan, Pulagam Srinivas, Shanmukh T, Rajaramesh, Prasad KVS, RameshT, Swarnalatha Mahapahra, Roja Sanchana, sayya, E.Sunitha, Ramakrishna M, Bobbadi Yernindra, Sandhya Patnaik, Rangula Sandhya, Radha, Pradeep Kumar, Lalitha Tekumalla, Rajasekhar, Ch.Venkatesh, E.Sujatha, Appalachari, Venkatesh Yadav, Sabbana Venkatesh, K.Pooja, P.Sri Kavya, Boby Abraham, Vijay Santosh Kumar, Divya Chinni, BhujangaRao, Shilpa Surana, Uma Vegesina, Ravi Teja, Gollapalli Jayanna, 
Manohar Rao YB, Chinarayudu Boya, Yogindra, and many emerging artists are settled in the places like Hyderabad, Baroda, and Mumbai, Delhi, Bangalore, Visakhapatnam, Kadapa with great aspiration and zeal.

\section{CONCLUSION}

The Telugu artists are self- generated and discerning modernity affiliated to their creative pursuits. The senior artists between 20 and 50's sought inspiration from mythology, folk and religion and immediate surrounding with native media of wash technique. The second generations of 60's and 70's adopted images from the child hood memories and rural and contemporary life. The third generation artists from 90's are much inclined to from urban and global realities and more experimental with different kind of media. Artists of Andhra Pradesh are eagerly waiting for off shoot of Lalit Kala Akademi to be installed through which art of Andhra Pradesh can get a fresh breeze and may get abundant opportunities to prove their creative potential.

\section{REFERENCES}

1. M.Rajaji(1978), "Siddha Hasthudu Damerla Rama Rao - Jeevistham Kala rishi”,Rajhmundry.

2. Telephone Interview with Teki Mrutyunjaya Rao, Artist from Rajahmundry, Student of Rajaji. Madeti.

3. Raman, A.S, "Modern Art in Andhra Pradesh" the Illustrated weekly of India, July 1964.

4. Vinod Kumar(1980), Andhra Scene Lalit Kala Contemporary 3.

5. A.Pydi Raju a monograph by AP Lailt Kala Academy 1978.

6. Telephone Interview with Sri Vijaya Kumar, member of Guntur "Pandavas" in Andhra Pradesh.

\section{Image Credits:}

1.Atmakuru Ramakrishna, Vijayawada.

2. Sunkara Chalapathi Rao, Visakhapatnam.

3. https://www.gallerythreshold.com/artist/v-ramesh. (Prof. V.Ramesh)

4. https://scroll.in/magazine (Ravinder G. Reddy)

6.Jagadeesh Thammineni

7. Santosh Pedagadi

8.JSP Govind.

9. Sograh Khurasani. 